\title{
Migration of DINP and DOP plasticisers from PVC sheets into food
}

\author{
M.M.K. Fouad \\ Chemical Engineering Department, Faculty of Engineering, Cairo University, Giza, \\ Egypt \\ A.M. El Sayed \\ National Research Centre, Dokki, Giza, Egypt \\ A.N. Mahdy \\ Chemical Engineering Department, Faculty of Engineering, Cairo University, Giza, \\ Egypt
}

\section{Keywords \\ Contamination, Plastics, \\ Packaging, Food}

\section{Abstract}

Over the last few decades, the use of plastics as packaging materials has increased due to their properties and processibility. On the other hand, as a result of contact of packed food with plastics, traces of plastic components may migrate into the food medium contaminating it and affecting consumers' health. This work concerns the study of migration of DINP and DOP plasticisers from PVC sheets into foodstuffs. PVC sheets using either type of plast cisers with different concentrations were prepared and then put in contact with different food simulants. Gravimetric analysis was used to determine the loss in plasticised PVC sheets upon immersion in food simulants.

Changes in mechanical properties of tested sheets were observed. IR was used in the detection of plastic components in food simulants. A comparison was held between the migration of DINP and DOP plasticisers into food simulants.
Environmental Management and Health

10/5 [1999] 297-302

C MCB University Press [ISSN 0956-6163]

\section{Introduction}

Over the last few decades the sale of packaged food products has greatly increased all over the world. More recently, it has been recognized that the migration of packaging materials into food may present health hazards for consumers.

The migration of residual monomers from polymers into foodstuffs and the factors affecting such migration were studied by several researchers (Witey and Collins, 1978; Varner et al., 1983; Diachenko et al., 1977; Philo et al., 1994; Hammarling et al., 1995). In all studies traces of monomers were detected in the foodstuffs or food simulants used.

Migration of stabilizers has also attracted scientists. Figg has studied the migration of organation stabilizer used in PVC into food simulants (Figg, 1980). The results confirmed the migration of stabilizer under study into the food simulant selected.

Researchers also studied the migration of DEHA (Samia, 1991), DEHP (Raouf, 1991), DBP , DEP (Page and Lacroix, 1995) and polymeric plasticisers (Laurence et al., 1988) from polymers into contact food or food simulants. Migration of plasticisers was confirmed in all preceding studies.

It is worth mentioning that the migration of plasticisers generally increases the migration of other additives. In response to this, this work is concerned with the migration of DINP and DOP plasticisers from plasticised PVC sheets into food simulants. The effect of temperature on the percent loss in plasticised sheets with or without using stabilizer was studied. Tests were carried to determine overall migration from plasticised PVC into food simulants. The effect of migration on mechanical properties was then studied. Finally IR was used to detect the presence of PVC and plasticiser in food simulant.

The current issue and full text archive of this journal is available at http://www.emerald-library.com

\section{Experimental work}

The experimental work has been carried out in five steps.

\section{Preparation of PVC sheets}

The PVC sheets were manufactured from PVC resin (K-70) kindly supplied by the Egyptian Petrochemical Company. Tribasic lead stearate of constant concentration of $2 \mathrm{phr}$ was used. DOP and DINP plasticisers were used with different concentrations ranging from $0-50 \mathrm{phr}$.

After mixing the desired formula of PVC sheets required, the mixture was extruded in a roll mill machine at a temperature of $160^{\circ} \mathrm{C}$ for plasticised samples and $180^{\circ} \mathrm{C}$ for unplasticised samples for a constant interval of three minutes with a constant thickness in most samples except for those used to study the effect of change in thickness. Thickness was changed from $0.04 \mathrm{~mm}$ to $1.2 \mathrm{~mm}$ by changing the distance between the two rolls. The sheets thus obtained were cut into square shaped test samples of $5 \mathrm{~cm}$ side length for investigating the effect of temperature on migration, while circular test samples of $5 \mathrm{~cm}$ diameter were used in migration test samples.

\section{Effect of temperature on PVC sheets plasticised with DINP and DOP}

There are a number of criteria to be considered in the selection of packaging materials. Among such criteria are the prevailing environmental conditions to which the product is exposed during distribution and storage. Such environmental conditions as temperature and relative humidity will dictate barrier properties required of the package.

Temperature plays a very important role in the amount of substance migration from plastic package into food. At high temperature certain physical and mechanical properties of the plastic material can be changed which might increase migration. 
$\overline{\text { M.M.K. Fouad, A.M. El Sayed }}$ and A.N. Mahdy

Migration of DINP and DOP

plasticisers from PVC sheets

into food

Environmental Management

and Health

10/5 [1999] 297-302
Experiments were performed to study the effect of temperature on percent loss in weight of PVC resin alone and the resin with thermal stabilizer. Tribasic lead stearate was used as thermal stabilizer. Experiments were also carried out to test the effect of heat on unplasticised PVC at different temperatures and heating duration and on PVC sheets plasticised with DOP and DINP.

Samples were weighed before being exposed to heating in the oven (wo). They were then heated in the oven at the required temperature and were weighed every 5 hours (wt). Percent change in weight was obtained by substituting in equation (1):

$$
\% \text { loss in weight }=\frac{w o-w t}{w o} \times 100
$$

It is worth mentioning that each result in this part of the work was obtained by taking the average of five samples exposed to the same condition for the same period of time.

\section{Overall migration from PVC sheets into food simulants}

Food simulants are usually used in preference to foods in migration tests for two basic reasons:

(1) The analytical procedure is usually simpler and easier to perform since identification of migration species in the presence of chemically complex mixture, as in the case of many foodstuffs, presents enormous problems.

(2) Using standard simulants, information obtained can be related to a wide range of foods.

The liquid test foodstuffs used in this study are those specified in all national and international or legal regulations. The simulants used are: distilled water, 1 percent sodium chloride solution, saturated sugar solution, 10 percent normal butanol solution and commercial ethanol.

Distilled water simulates non-acid foods. On the other hand, water, in some cases, is stored in plastic containers for long periods of time. In addition beverages, the main constituent of which is water, are usually packaged in PVC bottles. Even milk of different qualities and even liquid cream (30 percent fat content) is more realistically simulated in migration tests by aqueous test media than fatty simulants.

Saturated sugar solution simulates food containing high sugar percent as fruit juices, honey, sweets ... etc. which in a lot of cases are packaged in PVC films or containers. Distilled water was used for preparing the saturated sugar solution.

1 percent $\mathrm{NaCl}$ simulates foodstuffs with $\mathrm{pH}$ value of 5 while 10 percent $n$-Butanol simulates foods and medicine containing alcohol.

A simple gravimetric procedure was used in determining the quantity of material which has migrated from the plastic sample into the foodstuffs. Samples were weighed before immersion (wi) for one month in the food simulants listed above in the migration cell shown in Figure 1.

Test conditions involved maintenance of two-sided contact between test samples and contact phase.

Samples were washed to remove adhering food simulants and then dried. Final weights of the samples were then obtained (wt). The amount of material which has migrated from the plastic was then calculated as percent weight loss of the plastic sample by substitution in equation (1).

The effect of immersion in food simulants on mechanical properties of tested samples

Percent elongation and tensile strength were obtained to show the change in mechanical properties of the plastic samples due to the contact with food simulants.

The samples were cut into two individual dumbbell shapes by a fine-edge steel die of constant width of $(0.4 \mathrm{~cm})$.

\section{Detection of the presence of PVC and plasticiser in food simulants by using IR spectroscopy}

An IR spectrophotometer was used to detect the presence of PVC in food simulants.

\section{Results and discussion}

\section{Effect of temperature on test samples}

With foodstuffs packed in plastic materials, storage periods of several months at room temperature must be taken into consideration in spite of the intrusive utilization of cold stores and refrigerators in trade and households.

Instead of determining the migration under these conditions, high temperatures were applied on plastic samples for a period of five hours.

\section{Figure 1}

Simple migration cell

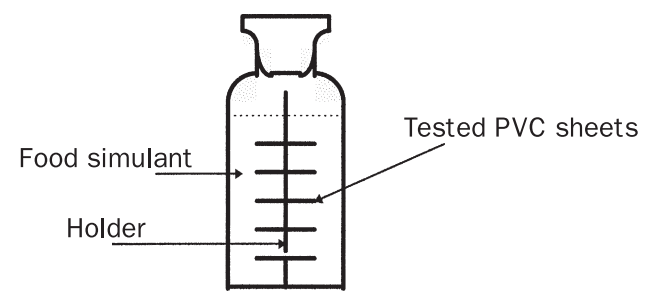


M.M.K. Fouad, A.M. El Sayed and A.N. Mahdy

Migration of DINP and DOP

plasticisers from PVC sheets

into food

Environmental Management

and Health

10/5 [1999] 297-302
In addition to this, packed foodstuffs in plastic bottles, containers, films and plastic stoppered containers are in some cases pasteurized by short-term heating before cooling in cool places.

Figure 2 shows the effect of applying a temperature of $100^{\circ} \mathrm{C}$ over a period of five hours on PVC resin and on the same quantity of resin added to 2 percent tribasic lead stearate as a thermal stabilizer. If one studies time-dependent course of percent change in weight of PVC resin, it will be found that it has a typical exponential trend resembling an isotherm, i.e. at the beginning, the increase of percent loss in weight per time is substantially greater than in the later stage. The Figure shows that there is almost no further loss in weight after two hours' exposure to a temperature of $100^{\circ} \mathrm{C}$. The percent loss in weight reached a final value of 0.275 percent after five hours.

The Figure also shows that the presence of 2 percent thermal stabilizer (tribasic lead stearate) decreases the loss in weight when subjected to the same conditions to which PVC resin alone was subjected. It reached a final value of 0.1 percent after five hours. This could be attributed to the fact that the thermal stabilizer resists and thus decreases the thermal cracking.

Figure 3 illustrates the effect of different temperatures on unplasticised PVC sheets (UPVC). Different temperatures were used within the range $50^{\circ} \mathrm{C}-150^{\circ} \mathrm{C}$.

As is clear from the results the percent loss in weight of UPVC is dependent greatly on both temperature and time.

While percent loss in weight of samples at $50^{\circ} \mathrm{C}$ after one hour was 0.01 percent, it reached 0.035 percent after five hours. On the other hand, when heating to a temperature of $150^{\circ} \mathrm{C}$ for five hours percent loss in weight reached a value of 0.1 percent, i.e. about ten times its value at $50^{\circ} \mathrm{C}$ and one hour. This could be attributed to the fact that the thermal cracking operation responsible for

\section{Figure 2}

Effect of presence of stabilizer on percent loss in weight upon heating at $100^{\circ} \mathrm{C}$

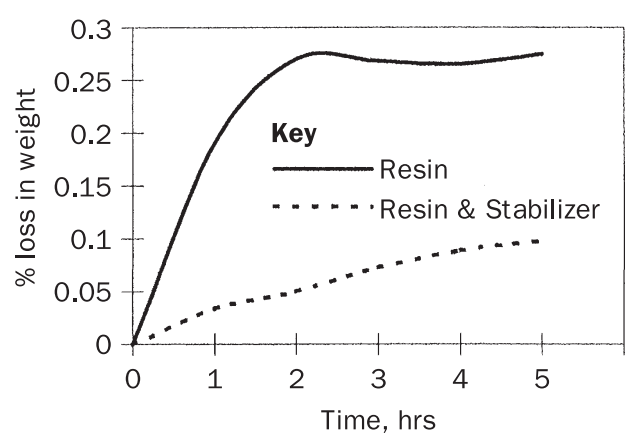

\section{Figure 3}

Effect of temperature on percent loss in weight of unplasticised PVC sheets

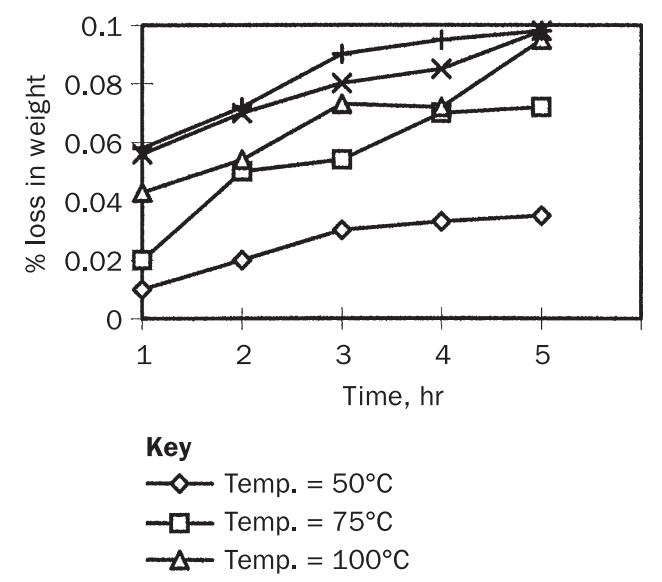

the breaking of the PVC bonds is an endothermic reaction that needs energy to proceed.

Figure 4 shows the effect of different temperatures $\left(50^{\circ} \mathrm{C}-150^{\circ} \mathrm{C}\right)$ on PVC sheets plasticised by either DOP or DINP plasticisers when applied for a duration of five hours. Different concentrations of plasticisers were tested within the range of 0-40phr.

Results obtained on using both plasticisers showed the same trend; the percent loss in weight of the samples under test was found to be proportional to both the concentration of the plasticiser and the applied temperature. However, on using DINP as a plasticiser the samples showed lower decrease in weight compared to the case when DOP was used. This could be attributed either to the fact that

\section{Figure 4a}

Effect of heating on PVC sheets plasticised with DOP

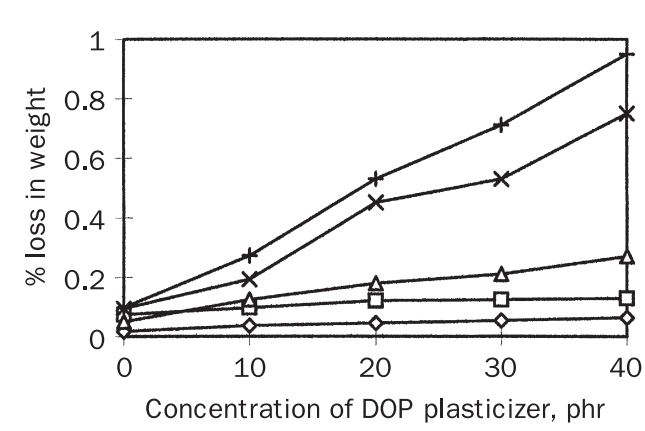

Key

$$
\begin{aligned}
& \diamond \text { Temp. }=50^{\circ} \mathrm{C} \\
& -\square-\text { Temp. }=75^{\circ} \mathrm{C} \\
& -\Delta \text {-Temp. }=100^{\circ} \mathrm{C} \\
& \leftarrow \text { Temp. }=125^{\circ} \mathrm{C} \\
& \text { 十 Temp. }=150^{\circ} \mathrm{C}
\end{aligned}
$$


M.M.K. Fouad, A.M. El Sayed and A.N. Mahdy

Migration of DINP and DOP

plasticisers from $P V C$ sheets

into food

Environmental Management

and Health

10/5 [1999] 297-302 $\overline{\text { Figure 4b }}$

Effect of heating on PVC sheets plasticised with DINP

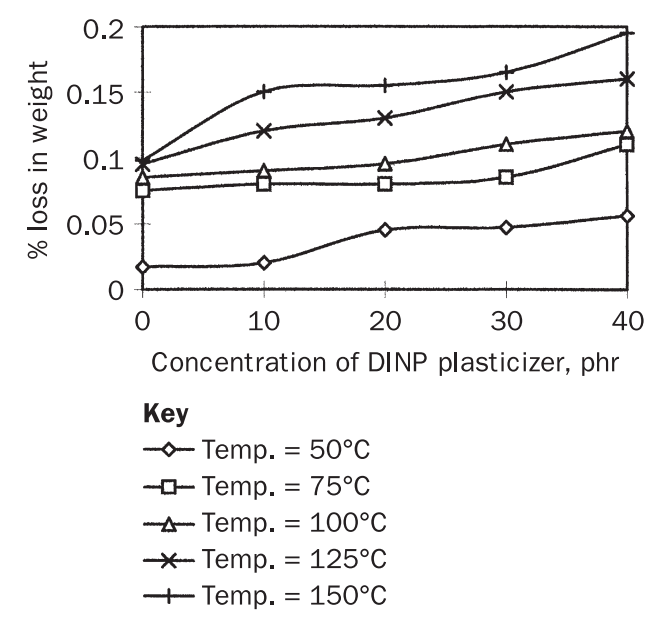

DINP is less volatile than DOP or the fact that DINP has a thermal stabilizing effect.

It is worth mentioning that the total percent loss in any sample is the summation of loss due to the volatility of the plasticiser and due to thermal cracking.

Percent loss in weight of the plasticiser was calculated using equation (2) and results are shown in Figure 5 for both plasticisers under study with different concentrations upon heating at $100^{\circ} \mathrm{C}$ :

$$
\begin{gathered}
\% \text { loss of plasticiser }= \\
\% \text { total loss }-\% \text { loss of UPVC }
\end{gathered}
$$

It is clear that the total percent loss in weight is affected by the percent loss in weight of plasticiser rather than thermal cracking. Again DINP showed lower percent loss in weight than DOP.

\section{Overall migration from plasticised PVC into food simulants}

Table I sums up the results obtained upon immersion of PVC sheets plasticised with

\section{$\overline{\text { Figure } 5}$}

Percent loss in weight of PVC sheets plasticised with DOP and DINP upon heating to $100^{\circ} \mathrm{C}$

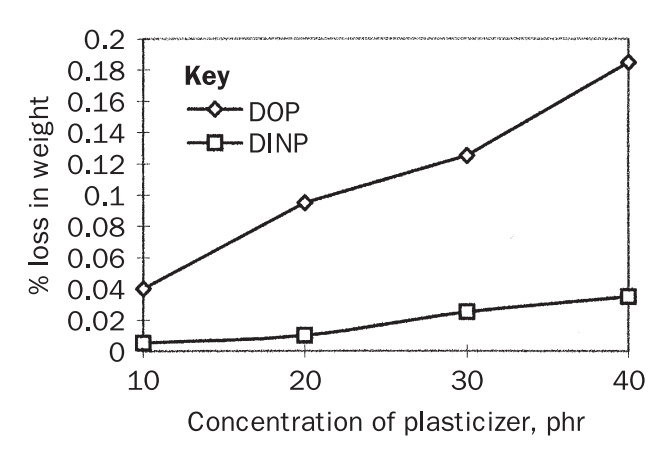

30phr DOP or DINP for one month in the food simulants used (distilled water, 1 percent $\mathrm{NaCl}$ solution, saturated sugar solution and N-butanol solution).

Quantifiable migration occurred from the polymer samples into all tested food simulants. Greater overall migration was observed in the case of using 10 percent $\mathrm{N}$ butanol solution as food simulant. This high effect could be attributed to the fact that both plasticisers have a certain solubility in alcoholic solutions.

The effect of the saturated sugar solution was found to come next after the N-butanol in terms of percent loss in weight. This could be due to the fact that organic materials are soluble in organic solvents, and as a matter of fact fermentation was noticeable after 15 days in spite of the fact that the cell was firmly closed. This fermentation might have led to the formation of either ethanol or acetic acid, which might have led to this high percent loss in weight.

However, least overall migration was observed in the case of using distilled water as simulant owing to its freedom from any organic or inorganic compounds which might affect the PVC sheets.

On the other hand, it is clear that the percent loss in weight of the tested sheets upon immersion was found to be generally higher upon using DOP plasticiser in case of all simulants used. This could be attributed to the fact that DINP is of higher molecular weight leading to strong bonding with PVC molecules, DINP is less volatile than DOP, in addition to the fact that DINP is more thermally stable than DOP.

To study the effect of thickness of the PVC sheets on migration, PVC samples plasticised with 50phr of DOP plasticiser have been prepared with different thicknesses $(0.4,0.6$, 0.8 and $1.2 \mathrm{~mm}$ ). This has been attained by changing the distance between the two rolls in the machine used in the manufacture of the PVC sheets. The samples were immersed in commercial ethanol for one month.

Figure 6 shows thickness having an inverse relation with migration as increase in thickness resulted in lower percent loss in weight. This might be due to the fact that decreasing thickness increases degree of swelling.

\section{Effect of immersion in food simulants on} mechanical properties of tested sheets For the purpose of testing the plasticiser permanence the physico-mechanical properties were determined on plasticised PVC test specimens after their total immersion in different food simulants for one month. 
$\overline{\text { M.M.K. Fouad, A.M. El Sayed }}$ and A.N. Mahdy

Migration of DINP and DOP

plasticisers from PVC sheets

into food

Environmental Management

and Health

10/5 [1999] 297-302
Results are included in Table II which shows a comparison between percent elongation and tensile strength of plasticised PVC sheets with 30phr DOP and DINP before and after contacting with food simulants.

The polymer, because of loss of plasticiser, shows change in mechanical properties; percent of elongation in most cases was found to decrease while tensile strength showed an increase.

It is considered that the plasticisers act by inducing a shift of the polar groups of polymer and plasticiser. The polar groups of the plasticiser molecule weaken the intermolecular force of the polymer molecules by inserting themselves between them and linking on the polymer dipoles so that molecular associations take place. Thus the rigid macromolecules relax, the chains become more mobile and elastic, losing parts of their stiffness.

\section{$\overline{\text { Table I }}$}

Percent loss of plasticised PVC sheets with time due to immersion in different food simulants

\begin{tabular}{llllllll}
\hline & & \multicolumn{7}{c}{ Time, days } \\
Food simulants & Type of plasticiser & \multicolumn{1}{c}{$\mathbf{5}$} & \multicolumn{1}{c}{$\mathbf{1 0}$} & $\mathbf{1 5}$ & $\mathbf{2 0}$ & \multicolumn{1}{c}{$\mathbf{2 5}$} & \multicolumn{1}{c}{$\mathbf{3 0}$} \\
\hline Distilled water & DINP & 0 & 0 & 0.001 & 0.002 & 0.002 & 0.0025 \\
& DOP & 0.0056 & 0.016 & 0.029 & 0.045 & 0.05 & 0.055 \\
$\mathbf{1} \% \mathbf{N a C l}$ & DINP & 0.005 & 0.01 & 0.013 & 0.019 & 0.028 & 0.03 \\
& DOP & 0.01 & 0.02 & 0.03 & 0.042 & 0.05 & 0.056 \\
\multirow{5}{*}{ Sugar solution } & DINP & 0.013 & 0.025 & 0.037 & 0.05 & 0.06 & 0.06 \\
& DOP & 0.021 & 0.05 & 0.082 & 0.105 & 0.112 & 0.112 \\
$\mathbf{1 0} \%$ n-butanol & DINP & 1.23 & 1.91 & 2.2 & 2.29 & 2.3 & 2.3 \\
& DOP & 4.8 & 7.28 & 7.8 & 7.82 & 7.85 & 7.97 \\
\hline
\end{tabular}

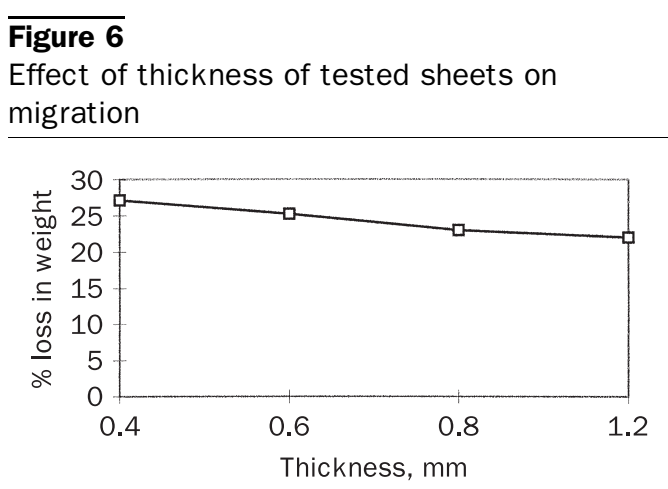

\section{Table II}

Effect of immersion of plasticised PVC sheets in food simulants on their mechanical properties

\begin{tabular}{|c|c|c|c|c|c|c|}
\hline \multirow{3}{*}{$\begin{array}{l}\text { Mechanical } \\
\text { properties } \\
\% \text { Elongation }\end{array}$} & \multirow{2}{*}{\multicolumn{2}{|c|}{$\begin{array}{l}\text { Without } \\
\text { contacting }\end{array}$}} & \multicolumn{4}{|c|}{ Mechanical properties after contacting } \\
\hline & & & \multirow{2}{*}{$\begin{array}{c}\text { Dist. water } \\
250\end{array}$} & \multirow{2}{*}{$\begin{array}{c}\text { Sugar sol. } \\
275\end{array}$} & \multirow{2}{*}{$\begin{array}{c}1 \% \mathrm{NaCl} \\
265\end{array}$} & \multirow{2}{*}{$\begin{array}{c}\text { 10\% N-But } \\
262.5\end{array}$} \\
\hline & $\mathrm{DOP}$ & 300 & & & & \\
\hline & DINP & 225 & 200 & 200 & 225 & 225 \\
\hline \multirow[t]{2}{*}{ Tensile strength } & DOP & 190 & 190 & 190 & 190 & 195 \\
\hline & DINP & 240 & 265 & 245 & 260 & 295 \\
\hline
\end{tabular}

The process could be very well explained by supposing that the PVC macromolecules have a spiral structure. Thus the plasticiser polarity is of great importance and is at the same time one of the conditions of good compatibility. Thus change in mechanical properties could be attributed both to the loss of plasticiser and to the change in the structure of PVC due to the immersion.

N-butanol, which showed the highest percent loss of plasticiser did not show the highest effect on mechanical properties. It is also clear that the effect of DINP is greater on tensile strength than DOP.

In the case of using distilled water as a simulant to food, percent elongation increased by the increase in concentration of plasticiser in PVC sheets and without contact with distilled water being higher than with contact with distilled water. It is hard to attribute this change in percent elongation only to loss of plasticiser; thus structure of PVC sheets must have been affected by immersion. On the other hand, tensile strength clearly decreases by increase of concentration of plasticiser and increases by contact with distilled water.

\section{Detection of food simulants by IR}

The presence of plastic materials in the food simulants under study was determined using IR spectroscopy and a summary of results obtained is shown in Table III.

For IR tests in the case of using distilled water, N-butanol and saline solution as food simulants peaks were detected at wavelengths $3,480 \mathrm{~cm}^{-1}, 2,080 \mathrm{~cm}^{-1}, 1,950 \mathrm{~cm}^{-1}$, and $200-500 \mathrm{~cm}^{-1}$ indicating the presence of $\mathrm{OH}$ groups from $\mathrm{H}_{2} \mathrm{O}, \mathrm{CH}_{2}$ or $\mathrm{CH}_{3}$ from $\mathrm{PVC}$, $\mathrm{C}=\mathrm{O}$ from DOP or DINP and an inorganic compound most probably from stabilizer.

However in the case of using sugar solution in addition to the above mentioned peaks, a peak is clear at the wavelength of $1,050 \mathrm{~cm}^{-1}$ indicating the presence of $\mathrm{C}-\mathrm{O}$ and $\mathrm{O}-\mathrm{H}$ groups which detect the presence of primary alcohol which might be due to fermentation.

As for PVC sheets after contacting with commercial ethanol presence of a peak at the wavelength $740 \mathrm{~cm}^{-1}$ was noticed, indicating that the migration of traces of PVC or VCM into commercial ethanol has occurred.

\section{Conclusion}

Based on the results of this work, gravimetric analysis was found to be useful in the study of the migration phenomenon in case of long period tests where change in weight is obvious, as in the case of high concentration of plasticisers. 
$\overline{\text { M.M.K. Fouad, A.M. El Sayed }}$ and A.N. Mahdy

Migration of DINP and DOP

plasticisers from PVC sheets

into food

Environmental Management

and Health

10/5 [1999] 297-302
Table III

Summary of IR detection of presence of plastic in food simulants

\begin{tabular}{|c|c|c|c|c|c|c|c|c|}
\hline Peak cm ${ }^{-1}$ & & Group & Substances & $\begin{array}{c}\text { Distilled } \\
\text { water }\end{array}$ & $\mathrm{NaCl}$ & $\begin{array}{l}\text { Sugar } \\
\text { solution }\end{array}$ & N-Butanol & $\begin{array}{c}\text { Commercial } \\
\text { ethanol }\end{array}$ \\
\hline 3,480 & & $\mathrm{OH}$ & $\mathrm{H}_{2} \mathrm{O}$ & + & + & + & + & + \\
\hline 2,080 & 12 & $\mathrm{CH}_{2}$ or $\mathrm{CH}_{2}$ & PVC & + & + & + & + & + \\
\hline 1,050 & , & $-\mathrm{OH}$ & Primary alcohol & - & - & + & - & - \\
\hline $540-780$ & -1 & $\mathrm{C}-\mathrm{Cl}$ & VCM & - & - & - & - & + \\
\hline $200-500$ & & Inorg. subs & Stabilizer & + & + & + & + & + \\
\hline
\end{tabular}

In case of using $\mathrm{PVC}$ as packaging material, DINP, although more expensive, is recommended to be used instead of DOP as it has a higher resistance to migration than DOP

Migration of plasticiser from plastic material into food resulted in change in mechanical properties of tested material and thus this change can be used as an indication of loss of PVC additives into food.

It is worth mentioning that, although in the presented work only aqueous food simulants were used, it should be noted that some components of plastics can also migrate into dry foodstuffs; thus one should not assume that packaging materials for such foodstuffs do not need to be tested.

Finally, PVC packaging material, although highly used all over the world, is not recommended as each of the monomers, stabilizers and plasticisers are subject to migration into packaged foods.

\section{References}

Diachenko, G.W., Breder, C.V., Brown, M.E. and Dennsion, J.L. (1977), "Gas liquid chromatographic headspace technique for determination of vinyl chloride in corn oil and three food simulating solvents", Journal of Association of Analytical Chemistry, Vol. 60 No. 2, pp. 570-8.

Figge, K. (1980), "Migration of components from plastics packaging materials into packed goods; test method and diffusion models", Progress in Polymer Science, Vol. 6 No. 2, pp. 187-252.

Hammarling, L., Gustavsson, H. and Svensson, K. (1995), "Polystyrene food packaging is not a problem under normal conditions", Var Foda, Vol. 47 No. 1, pp. 26-8.
Laurence, C., Angela, J. and Gohn, G. (1988), "Migration from plasticised films into foods. Use of polymeric plasticisers and lower levels of Di-2-Ethyloxyl adipatic plasticiser in PVC films to reduce migration into foods", Food Additives and Contaminants, Vol. 5 No. 3 , pp. 277-82.

Page, B.D. and Lacroix, G.M. (1995), "The occurrence of phthalate ester and Di-2-Ethylhexyl adipate plasticisers in Canadian packaging and food sampled in 1985-1989”, Food Additives and Contaminants, Vol. 12 No. 1, pp. 129-51.

Philo, M.R., Jickells, S., Damant, A.P. and Castle, L. (1994), "Stability of plastics monomers in food simulating liquids under European Union migration test conditions", Journal of Agricultural and Food Chemistry, Vol. 42 No. 7, pp. 1497-501.

Raouf, M.H. (1991), "Toxic-pharmacological evaluation of plastics-made pharmaceuticals", Bulletin of Egyptian Packaging Development Association (EDPA), Vol. 50 No. 1, pp. 27-9.

Samia, M.M. (1991), "Hygienic and environmental hazards of packaging material and its wastes: methods of protection", Bulletin of Egyptian Packaging Development Association (EDPA), Vol. 50 No. 1, pp. 26-30.

Varner, S.I., Breder, C.V. and Fazio, T. (1983), "Determination of styrene migration from food contact polymers into margarine using azeotropic distillation and gas chromatography”, Journal of Association of Analytical Chemistry, Vol. 66 No. 8, pp. 1067-75.

Witey, J.R. and Collins, P.G. (1978), "Styrene monomers in foods. A limited Canadian survey", Bulletin of Environmental Contamination Toxicology, Vol. 19 No. 2, pp. 86-91. 